\title{
A competitividade internacional e a desoneração tributária do trabalho formal no Brasil
}

\author{
International competitiveness and tax \\ exemption of formal labour in Brazil
}

\author{
Lourival José de Oliveira ${ }^{[a]}$, Renata Calheiros Zarelli[ ${ }^{[b]}$ \\ [a] Doutor em Direito das Relações Sociais pela Pontifícia Universidade Católica de São Paulo (PUC-SP), \\ docente do curso de Graduação em Direito da Universidade Estadual de Londrina (UEL), Londrina, \\ PR - Brasil, e-mail: lourival.oliveira40@hotmail.com \\ [b] Advogada, pós-graduada em Direito e Processo do Trabalho pelo Instituto de Direito Constitucional \\ e Cidadania (IDCC), Londrina, PR - Brasil, e-mail: renata.zarelli@gmail.com
}

\section{Resumo}

A competitividade de produtos internacionais com os produzidos nacionalmente está a proporcionar um processo "precoce" de desindustrialização no Brasil. Esse processo está vinculado ao recuo na contratação de novos postos de trabalho e à dispensa dos empregados contratados e, ainda, associado à utilização de tecnologias poupadoras de mão de obra. Com isso, a Presidenta da República recentemente expediu sete decretos e duas medidas 
provisórias, a fim de garantir o fortalecimento econômico e estimular a indústria nacional a enfrentar a crise financeira mundial e o processo de desindustrialização. Isso com a consequente desoneração tributária do trabalho formal, com vistas a garantir novos empregos e a formalizar as já existentes e evitar a subcontratação de trabalhadores por meio da terceirização, que é uma forma de precarização desses direitos. Tais medidas visam também a ampliar a produção nacional, barateando os custos da produção e dos preços do produto, e garantir de forma sustentável o desenvolvimento econômico nacional. O Estado tem a responsabilidade de compatibilizar a economia e a garantia dos direitos sociais, a fim de obter um desenvolvimento econômico nacional sustentável, sempre visando a frear possíveis violações aos direitos sociais. Na elaboração deste artigo, foi utilizada a metodologia da pesquisa por meio do estudo descritivo, exploratório e bibliográfico do tema, com a consequente análise dos dados e informações por meio de um enfoque qualitativo.

Palavras-chave: Crise econômica. Desindustrialização. Competitividade internacional. Desoneração tributária. Direitos sociais.

\section{Abstract}

The international competitiveness of products with the products produced nationally is to provide a process "early" de-industrialization in Brazil. This process is linked to the reduced recruitment of new employment and dismissal of employees hired, and still associated with the use of technologies that save manpower. Thus, the President of the Republic recently issued seven decrees and two interim measures to ensure economic empowerment and stimulate the domestic industry to face global financial crisis and the process of deindustrialization with the consequent tax exemption of formal work, with a view to ensure new jobs and the formalization of existing, and prevent the supply of workers through outsourcing, which is a form of instability of these rights. Such measures also aim to expand domestic production, reducing production costs and product prices, and ensure a sustainable national economic development. The State has the responsibility to reconcile the economy and guarantee of social rights in order to achieve a sustainable national economic development, always seeking to curb possible violations of social rights. In preparing this article the methodology of the research through a descriptive, exploratory and 
literature of the subject, with the subsequent analysis of data and information through a qualitative approach.

Keywords: Economic crisis. De-industrialization. International competitiveness. Tax exemption. Social rights.

\section{Introdução}

É sabido por muitos que os direitos sociais previstos nas Constituições Federais de 1934 até 1988 e na Consolidação das Leis Trabalhistas (CLT), de 1943, foram influenciados pelas Constituições do México de 1917 e da Alemanha (Weimar) de 1919, ambas "constituem referências internacionais para a instauração de novo modelo de Estado - o Estado Social de Direito" (LEDUR, 2009, p. 69).

A partir desse momento, passa-se a exigir do Estado a garantia do usufruto dos direitos sociais "por aqueles a quem o sistema social e econômico não garante o mínimo existencial, base necessária para que o indivíduo possa desenvolver-se com autonomia" (LEDUR, 2009, p. 70).

Vale lembrar também que a Constituição da República Federativa do Brasil de 1988, conforme enuncia José Felipe Ledur (2009, p. 70)

deu um salto qualitativo de extraordinário significado no terreno dos direitos sociais ao incluí-los no rol dos fundamentais e porque reconheceu novos direitos, resultantes da influência do movimento social na convocação da Assembléia Nacional Constituinte e no desenvolvimento dos seus trabalhos.

Por vezes, é possível observar na simples leitura da atual Constituição Federal que os direitos sociais, por possuírem estreita relação com o direito ao trabalho, são até confundidos com este. Entretanto, os direitos sociais são um gênero que abrange outros direitos, tais como 
moradia, segurança, alimentação, entre outros, e o Direito do Trabalho é uma das espécies desses direitos sociais.

Outro ponto a ser levantado é quanto à globalização, que será explanada em dois sentidos: jurídico e o econômico, sendo aquele, conforme definido por Junior (apud PIOVESAN, 2004, p. 39),

o deslocamento da capacidade de formulação de definição e de execução de políticas públicas, antes radicada no Estado-nação, para arenas transnacionais ou supranacionais, decorrentes da globalização econômica e de seus efeitos sobre a extensão do poder soberano.

A globalização econômica, segundo Hesse (apud PIOVESAN, 2004, p. 42),

significa que as fronteiras entre países perdem importância, quando se trata de decisões sobre investimentos, produção, oferta, procura e financiamentos. As conseqüências são uma rede cada vez mais densa de entrelaçamento das economias nacionais, uma crescente internacionalização da produção, no sentido de que os diferentes componentes de um produto final passam a ser manufaturados em diferentes países, e a criação de mercados mundiais integrados para inúmeros bens, serviços e produtos financeiros.

Assim, a globalização econômica é responsável pela abertura de mercados internacionais e transferências de empresas dos países desenvolvidos para os países em desenvolvimento, em razão do baixo custo da produção e de mão de obra barata. Isso, em resposta à elevação do consumo em todo o mundo e da necessidade de baratear os custos da produção e obter maiores lucros.

No Brasil não é diferente. A crescente demanda de bens de consumos, tais como, roupas, eletrodomésticos, veículos, em razão do aumento da renda per capita da população brasileira, acarretou a inserção de novos produtos importados no país. Com isso, as indústrias nacionais 
não conseguem atingir o mesmo preço em razão da alta carga tributária e dos elevados custos trabalhistas decorrentes da legislação brasileira.

Nesse sentido, o jornal Valor Econômico publicou, em abril de 2012, que o Brasil tem o quinto menor custo de produção em ranking de 14 países, ficando a frente de Alemanha, França, Reino Unido e Estados Unidos. Todavia, está abaixo de China e Índia. Assim,

segundo a pesquisa, o custo de mão de obra da indústria de manufaturados que soma salários, direitos trabalhistas e benefícios usualmente concedidos pelas empresas - no Brasil é o dobro da do México e mais que duas vezes e meia o custo chinês. $O$ dispêndio com mão de obra na Índia é quase um quarto do brasileiro (WATANABE, 2012).

Em decorrência de tais fatos, os Estados nacionais tentam, com a implantação de algumas medidas, conter o processo de desindustrialização nacional, a fim de garantir que as indústrias e as empresas nacionais se mantenham firmes diante da competitividade internacional. Dentre outras, foram tomadas medidas pela Presidenta da República, no que tange à redução das alíquotas para financiamentos junto ao BNDES e quanto à desoneração tributária na folha de pagamentos dos trabalhadores formais.

Além disso, o propósito do Estado nacional é também evitar o desemprego estrutural, haja vista que já existe um processo de desindustrialização em determinados ramos de atividades (por exemplo, têxtil) que detêm grande quantidade da força de trabalho nacional e formal.

Dessa forma, o objetivo deste trabalho é discutir, de forma breve, as recentes providências adotadas pela Presidenta da República em abril de 2012. Isso será feito a fim de demonstrar que a desoneração tributária será uma das constantes medidas a longo prazo que deverão ser implantadas pelo Estado Nacional, de modo a conter a desindustrialização nacional, a possível influência da crise econômica mundial no Brasil, bem como os possíveis retrocessos quanto aos direitos trabalhistas garantidos nas relações de emprego. 


\section{A "possível" crise da desindustrialização nacional em decorrência da perda da competitividade nacional}

A "desindustrialização" teve seu estudo aprofundado a partir da "doença holandesa" (Dutch disease), ocorrida em meados da década de 1970 na Holanda. De acordo com Nassif (2006, p. 74),

a "doença holandesa" original está relacionada a um fenômeno real ocorrido na Holanda, nos anos 1970, quando a descoberta de grandes fontes de gás natural provocou uma forte realocação dos recursos na economia do país. No médio prazo, no entanto, o boom das vendas externas da commodity levou a uma enorme apreciação real do florim holandês e, por conseguinte, à depressão das exportações industriais do país. Após a ocorrência real do problema na Holanda, a teoria da Dutch disease foi desenvolvida pioneiramente por Corden e Neary (1982). Para esses autores, uma economia padece da doença holandesa quando a rentabilidade de um ou mais setores é fortemente comprimida como decorrência de um boom ocorrido em determinadas indústrias produtoras de bens ou serviços comercializados (traded goods). Jones e Neary (1984, p. 25) mostraram também que a retração dos demais setores da economia pode ser ainda mais acentuada, caso o efeito-gasto decorrente do boom aumente desproporcionalmente a rentabilidade dos setores que produzem bens não-comercializados (non-traded goods).

Segundo Rowthorn e Wells (1987 apud NASSIF, 2006), o processo de desindustrialização "é definido como um fenômeno caracterizado principalmente pela retratação relativamente expressiva do emprego no setor manufatureiro vís-à-vís os demais setores, notadamente o de serviços".

É necessário lembrar que a diminuição da participação do emprego no setor manufatureiro está associada à "absorção de tecnologias poupadoras de mão de obra”, em virtude da possibilidade de padronização dos produtos, e ao "elevado aumento da produtividade em relação ao de serviços" (ROWTHORN; RAMASWAMY, 1999 apud SONAGLIO et al., 2010). Nesse sentido, para Nassif (2006, p. 75) 
o principal argumento é que o ritmo mais intenso de crescimento da produtividade do setor manufatureiro frente aos demais setores em economias avançadas provoca queda acentuada dos preços relativos dos bens industrializados e, por conseguinte, um forte estímulo à demanda desses produtos, mais do que compensando os níveis de elasticidade-renda marginalmente inferiores a um, observados nesses países. Paralelamente, o ritmo intenso da produtividade do setor manufatureiro explica a queda relativa do emprego gerado nesse setor, em virtude da introdução de técnicas poupadoras de mão-de-obra. Nesse caso, a desindustrialização é paradoxalmente um fenômeno tecnológico, já que a indústria (ainda) constitui a principal fonte de progresso técnico.

Os autores Rowthorn e Wells (1987 apud NASSIF, 2006, p. 76) testaram empiricamente as circunstâncias que caracterizaram o processo de desindustrialização nos países industrializados durante o período de 1963-1994. Dentre outras conclusões, a situação atual do Brasil amolda-se à seguinte característica:

as evidências sugerem que a concorrência com importados provenientes dos países em desenvolvimento (em geral intensivos em trabalho e/ou recursos naturais) exerce um efeito marginal na queda da participação do emprego manufatureiro. Em última instância, seu principal impacto é fomentar a produtividade do setor manufatureiro dos países avançados, provocando maior especialização em produtos intensivos em capital e/ou de alta tecnologia, em geral poupadores de mão-de-obra.

Ocorre que o processo de desindustrialização, segundo Nassif (apud SONAGLIO et al., 2010), "não pode ser entendido como um efeito negativo, seja em relação ao crescimento de longo prazo da economia ou em relação ao bem-estar da sociedade".

Nesse sentido, para o autor, o que se espera desse fenômeno "é uma tendência natural do processo de desenvolvimento econômico e se 
manifesta com a perda da importância da indústria para o setor de serviços, em termos de emprego e de oferta total".

Sonaglio et al. (2010, p. 348) comentam sobre a desindustrialização e suas consequências no setor de serviços:

a análise da composição do emprego no setor de serviços indica um crescimento nas vagas dos segmentos de média e baixa tecnologia, indicando que o processo de desindustrialização ocorrido na economia brasileira não é derivado da trajetória virtuosa do desenvolvimento, pois as mudanças estruturais mostram perda de representatividade dos setores industriais de maior dinamismo, ao passo que os serviços de menor produtividade ganham espaço.

Entre os economistas anteriormente enunciados, não é unânime a posição de que o Brasil está enfrentando um processo de desindustrialização. Entretanto, as evidências expostas indicam que a longo prazo, em decorrência "da valorização da moeda brasileira em relação ao dólar em termos reais" e da "perda de competitividade industrial" (NASSIF, 2006, p. 73), o Brasil entraria em um processo precoce de desindustrialização.

\section{Medidas tomadas pelo Brasil diante da crise}

Nesse sentido, em decorrência da crise mundial econômica e financeira de 2008, os países desenvolvidos e em desenvolvimento, bem como a Organização Internacional do Trabalho (OIT), estão em constante discussão acerca das consequências que a crise acarretou e ainda poderá acarretar a tais países, no que tange a oportunidades de trabalho e à recuperação econômica.

A $17^{a}$ Conferência Interamericana de Ministros do Trabalho (CIMT), ocorrida em 31 de outubro e $1^{\circ}$ de novembro de 2011, com a participação dos países do Grupo de Trabalho I, que inclui o Brasil, discutiram 
sobre o tema "Trabalho decente para enfrentar a crise econômica global com justiça social para uma globalização equitativa" ${ }^{1}$.

A principal preocupação dos ministros é quanto aos impactos nos níveis e na qualidade do emprego. Eles propuseram promover soluções inovadoras, que coloquem o trabalho decente e a proteção social como pilares fundamentais do desenvolvimento.

Ao emanarem o relatório final, incluíram algumas recomendações para a elaboração de um plano de ação:

a) enfatizar a permanente necessidade de combater a informalidade e criar mais oportunidades de trabalho decente no setor formal, por meio de uma combinação de políticas educacionais, sociais, econômicas e de emprego;

b) continuar a reconhecer a importância das micro, pequenas e médias empresas, que geram prosperidade e inclusão social, e apoiar o apelo às instituições financeiras internacionais e regionais, para que aumentem os empréstimos e expandam o acesso ao crédito, conforme foi mencionado na Quinta Cúpula das Américas;

c) continuar a compartilhar as melhores práticas da região e a implementar programas destinados à crise de emprego e à violência juvenil, inclusive os esforços nos Ministérios do Trabalho, para oferecer oportunidades de emprego para os jovens. Os grupos de jovens fora da escola, subempregos e ex-membros de quadrilhas devem ser considerados e atendidos. As associações com instituições educacionais e de capacitação devem ser fortalecidas, a fim de melhorar a educação e as competências dos jovens, bem como as associações com o setor privado;

d) manter o apoio da CIMT ao Haiti, em virtude do devastador terremoto de janeiro de 2010;

1 ORGANIZAÇÃO DOS ESTADOS AMERICANOS. Conselho Interamericano de Desenvolvimento Integral (CIDI). 2011. Disponível em: <http://www.oas.org/ddse/english/cpo_trab_grupo1.asp>. Acesso em: 29 jun. 2012. 
e) fortalecer políticas públicas, programas e ações de prevenção e eliminação do trabalho infantil e do trabalho forçado, bem como compartilhar as melhores práticas da região; dentre outras.

Graças às inúmeras influências - processo precoce de desindustrialização e as recomendações do Grupo de Trabalho I da OIT -, a presidenta Dilma Roussef no início de abril de 2012 emanou duas medidas provisórias e sete decretos com ações para fortalecer a economia e estimular a indústria nacional. Não se tratará de todas as medidas em vigência, haja vista que o presente trabalho visa às medidas adotadas especificamente à desoneração tributária no trabalho formal.

A dificuldade do crescimento da economia brasileira tem sido pautada, como já tratado anteriormente, pela ocorrência da perda da competitividade da produção nacional de determinado setores industriais (têxtil, construção civil, etc.) para os produtos importados de países em desenvolvimento, como China e a Índia, essa última principalmente voltada para a área de tecnologia.

No sentido de serem proativas ao processo de desindustrialização do parque industrial brasileiro, especificamente as indústrias têxteis, as federações das indústrias da região Sul do Brasil - FIEP/Paraná, FIEP/ Rio Grande do Sul e FIEP/Santa Catarina - se reuniram para discutir soluções para o setor têxtil e de vestuário, haja vista a concorrência desleal dos produtos advindos, principalmente, da China ${ }^{2}$.

Não é a toa que as indústrias multinacionais estão transferindo sua linha de produção para países como China e Índia, em virtude do custo de produção, associado à legislação trabalhista e tributária precária e à "finitude" de recursos naturais e de mão de obra barata. Tais situações

2 FEDERAÇÃO DAS INDÚSTRIAS DO PARANÁ - FIEP. Indústria da região Sul busca soluções para o setor têxtil e de vestuário. Disponível em: <http://www.agenciafiep.com.br/noticia/industria-daregiao-sul-busca-solucoes-para-o-setor-textil-e-de-vestuario/>. Acesso em: 29 jun. 2012.

Rev. Direito Econ. Socioambiental, Curitiba, v. 3, n. 2, p. 355-373, jul./dez. 2012 
são demonstradas pelo documentário China Blue $e^{3}$, lançado em 2005 pelo diretor Micha Peled, em que são acompanhadas duas jovens chinesas que trabalham para uma indústria de jeans. O documentário retrata a falta de dignidade humana nas condições de trabalho dos chineses e a escravidão na modernidade.

Visando ao fortalecimento da economia brasileira e à necessidade de auxiliar as empresas nacionais assegurando a competitividade em mercados externos, cabe ao Estado orientar as ações pertinentes ao momento em que vivemos a "desindustrialização precoce no Brasil".

Com vistas à fortificação do trabalho formal, foi tomada a ação de alteração da alíquota das contribuições previdenciárias sobre as folhas de salários devidas pelas empresas, diminuindo os custos da produção, conforme tratado na Medida Provisória n. 563, de 3 de abril de 2012.

Tal medida determinou que, até 31 de dezembro de 2014, as empresas (hoteleiras; de tecnologia - desenvolvimento de sistemas, programação, jogos eletrônicos, suporte técnico e manutenção de computadores, etc. -; call center; moveleiras; elétricas; fabricação de ônibus; dentre outras) terão o privilégio da redução da alíquota das contribuições previdenciárias, antes de $20 \%$ para $1 \%$ ou $2 \%$ sobre o valor da receita bruta, excluídas as vendas canceladas e os descontos incondicionais concedidos. A justificativa dada é a implantação de uma indústria forte, com aumento na produção, diminuição dos postos de trabalho e permitindo a inclusão digital da população brasileira.

As exigências da desoneração da folha de pagamentos ressaltam a necessidade de incentivos à formalização das relações de trabalho, discutidos pelos Ministros do Trabalho CIMT, e, na intenção de desonerar a carga tributária atribuída às atividades industriais, a contratação de novos empregados e a manutenção dos contratados.

Outro ponto atribuído à medida de desoneração tributária é quanto à ampliação da contratação de trabalhadores com vínculos formais

3 PELED, M. China Blue. Disponível em: <http://teddybearfilms.fatcow.com/2011/09/01/chinablue/>. Acesso em: 29 jun. 2012. 
de emprego, pois diminuiria a subcontratação de trabalhadores por meio da terceirização, que está associada à precarização das relações de trabalho ${ }^{4}$.

A Medida Provisória n. 563/2012 trata do setor automobilístico e institui o Programa de incentivo à Inovação Tecnológica e Adensamento da Cadeia Produtiva de Veículos Automotores (Inovar-Auto). Tal programa visa à redução da base de cálculo do Imposto sobre Produtos Industrializados (IPI) incidente aos veículos automotores, tratores, caminhões, dentre outros.

Todas as ações tomadas nessa medida provisória têm por escopo a necessidade de intensificar a competitividade da indústria brasileira no âmbito interno e internacional, pois sua ausência poderia acarretar, nos próximos meses ou anos, o fechamento de fábricas, a redução na produção industrial e, consequentemente, a perda de postos de trabalho.

Além disso, ocorreram algumas reduções de taxas e ampliação de prazos, anunciadas pelo Banco Nacional do Desenvolvimento (BNDES), para estimular o investimento da indústria brasileira. Tais propostas visam a uma redução significativa do custo de seus financiamentos para máquinas e equipamentos.

A título de exemplo, com a prorrogação do prazo do Programa BNDES PSI ${ }^{5}$ para mais um ano, até dezembro de 2013, com redução de ta-

4 A terceirização lícita no Brasil está regulamentada em alguns dispositivos, quais sejam: art. 455/ CLT, que trata da empreitada e da subempreitada; Súmula n. 331/TST (atualizada em 2011), que determina as formas lícitas de terceirização, bem como a terceirização na Administração Pública; Lei n. 6.019/1974, que dispõe sobre o trabalho temporário (intermediação de mão de obra); Lei n. 7.102/1983, que trata dos serviços de vigilância; Decreto n. 200/1967, que dispõe sobre a terceirização na Administração Pública; e, por fim, a Lei n. 9.472/1997, que trata da terceirização nos serviços de telecomunicações. A intenção da medida adotada pela Presidenta da República é legalizar as formas de trabalho adotadas nas empresas que se utilizam da terceirização, muitas vezes ilícita. Assim, haja vista que os princípios da dignidade da pessoa humana e da não mercantilização do trabalho vedam que o trabalho seja considerado mercadoria (o trabalho humano não é mercadoria) e a coisificação do trabalhador ou o aluguel da sua força de trabalho por outrem (RESENDE, R. Direito do trabalho esquematizado. 2. ed. São Paulo: Método, 2012. p. 191).

5 É um programa vinculado ao BNDES, que financia a produção e a aquisição isolada de máquinas e equipamentos novos, de fabricação nacional, credenciados no BNDES, inclusive agrícolas, e o capital de giro a eles associados; aquisição de ônibus, caminhões, chassis, caminhões-tratores,

Rev. Direito Econ. Socioambiental, Curitiba, v. 3, n. 2, p. 355-373, jul./dez. 2012 
xas, aumento de prazos e dos níveis de participação, os juros para a aquisição de máquinas e equipamentos caíram de $8,7 \%$ para $7,3 \%$, no caso de grandes empresas, e de $6,5 \%$ para $5,5 \%$, no caso de micro, pequenas e médias empresas.

O BNDES reduziu ainda as taxas também para empresários autônomos, por meio do Programa BNDES Procaminhoneiro, que financia veículos para o caminhoneiro autônomo, reduzindo a taxa de $7 \%$ para $5,5 \%$. Assim como para as taxas na aquisição de ônibus e caminhões, de $10 \%$ para $7,7 \%$, além de aumentar o prazo de amortização de 96 meses para 120 meses.

Ainda nesse sentido, o Decreto n. 7.713 de 3 de abril de 2012 trouxe a margem de preferência para as compras governamentais realizadas no âmbito da Administração Pública Federal para aquisição de fármacos e medicamentos. Na mesma semana, o Ministério da Saúde ${ }^{6}$ comentou que a medida proposta pelo "governo federal espera estimular o desenvolvimento e a produção nacional de medicamentos, fármacos, insumos e, até o final deste semestre, de equipamentos e dispositivos médicos".

E por fim, dentre as medidas emanadas pela Presidenta da República, o Decreto n. 7.709, de 3 de abril de 2012, também lançou a margem de preferência pela indústria nacional na aquisição de equipamentos como retroescavadeira e motoniveladora, visando ao desenvolvimento nacional sustentável da indústria nacional relacionada à construção civil.

O que se espera com todas as medidas propostas é a ampliação da produção nacional, nos mais diversos setores da economia brasileira, o que acarreta em aumento da força de trabalho, geração de empregos

carretas, cavalos-mecânicos, reboques, semirreboques, aí incluídos os tipos Dolly, tanques e afins, novos de fabricação nacional e credenciados no BNDES; aquisição de máquinas e equipamentos novos, de fabricação nacional, credenciados no BNDES. BANCO NACIONAL DE DESENVOLVIMENTO ECONÔMICO E SOCIAL - BNDES. Associados a projeto de investimento. Disponível em: <http:// www.bndes.gov.br/SiteBNDES/bndes/bndes_pt/Institucional/Apoio_Financeiro/Programas_e_ Fundos/Psi/psi_bk.html>. Acesso em: 28 maio 2012.

6 IMPRENSA NACIONAL. Ministério da Saúde dará preferência a produtos nacionais em compras públicas. Disponível em: <http://www2.planalto.gov.br/imprensa/noticias-de-governo/ministerioda-saude-dara-preferencia-a-produtos-nacionais-em-compras-publicas>. Acesso em: 5 abr. 2012. 
novos e formalização dos já existentes. Além disso, há o barateamento dos custos da produção e dos preços do produto final, para que haja um desenvolvimento nacional sustentável e que tenha condições de competir nacionalmente e até em nível internacional.

\section{Participação do Estado diante da competitividade internacional e o processo "precoce" de desindustrialização no Brasil}

O papel do Estado diante da desindustrialização nacional, e especificamente a crise mundial, nas palavras de Faria (apud MEDEIROS, 2010, p. 11):

na medida em que a instituição estatal passa a representar, inesperadamente, a solução, deve-se construir e fortalecer novas alianças sociais que reorientem as políticas governamentais de geração e proteção de emprego e renda, concedendo não apenas iguais oportunidades, mas iguais condições, principalmente diante do anacronismo das atuais formas de controle e gestão do Estado-nação, o que termina levando à perda da centralidade e exclusividade do ordenamento jurídico estatal, pois o verdadeiro estado democrático deve ter como objetivos a socialização da política e do poder.

Assim, com a necessidade de afirmar sua soberania tenta-se com tais medidas evitar um agravamento do processo de desindustrialização nacional, a fim de garantir a sobrevivência das indústrias brasileiras, sejam grandes, médias ou pequenas, para que continuem a crescer e a gerar novos empregos e ainda formalizem os já existentes.

Com isso, evitar-se-á o desemprego estrutural que ocasiona um circulo virtuoso, com problemas de geração de renda e a consequente intervenção do Estado para garantir o mínimo existencial a tal população. Há, também, a diminuição no consumo em geral (bens supérfluos), decaindo ainda mais a produção e consequentemente vindo o desemprego. 
Outro ponto se dá quanto à redução dos tributos às empresas de grande, médio ou pequeno porte. Tais custos no Brasil são extremamente elevados, e isso a longo prazo inviabilizará qualquer reabilitação econômica e estrutural das empresas nacionais se não houver uma intervenção do Estado nesse sentido. A redução da carga tributária é de grande importância para o crescimento econômico do país, pois age diretamente na diminuição do custo da produção e no aumento da produtividade, o que gera a ampliação do número de empregos.

Ainda nesse sentido, é papel do Estado investir, isolada ou conjuntamente com as empresas privadas, na infraestrutura do país. Isso pode acontecer por meio do capeamento de novas estradas, na ligação de rodovias interestaduais e estaduais, ou na criação de ferrovias para o transporte de cargas, produtos e matérias-primas, com o escopo de proporcionar uma ligação de diferentes regiões e cidades do país, o que consequentemente barateia o custo do produto final.

Vale ressaltar que é responsabilidade do Estado investir em infraestrutura, com a implantação de novas estradas, o recapeamento das existentes, instalação de metrôs, transporte público de baixo custo. Isso baratearia os custos de logística da produção e do transporte dos trabalhadores. Também deveria se investir em saúde e educação da população, a fim de garantir a todos um aumento do conhecimento técnico e científico e, ainda, proporcionar um investimento em projetos científicos, no sentido de buscar novos caminhos tecnológicos futuramente.

Nesse sentido, o papel do Direito positivo diante da desindustrialização nacional e em decorrência da crise financeira mundial é o de repensar seus modelos e "práticas intervencionistas, buscando um maior consenso civilizatório de convivência social". Assim, "garante a prevalência dos direitos sociais duramente alcançados, como também dos mecanismos protetivos do emprego e de geração de renda, ensejando uma proteção social mais significativa" (MEDEIROS, 2009).

Assim, diante da preocupação da precarização das relações do trabalho em nível mundial (Organização Internacional do Trabalho - OIT), e ainda levando-se em conta que a proteção do trabalho é uma obrigação 
do Estado no sentido de atuar "normativamente e na fiscalização das condições e padrões legais das relações laborais", bem como em decorrência da realidade econômica existente, conforme descrito por Cunha (2009, p. 354), poderá se provocar

redefinições profundas do direito do trabalho e da justiça laboral na mudança de percepção sobre os direitos mínimos dos trabalhadores e as diversas modalidade de contrato de trabalho; ao mesmo tempo em que fiscalizará as condições mínimas do trabalho e garantirá os direitos trabalhistas, operará o Estado uma flexibilização nos modos e características da atividade laborais, com o objetivo de compatibilizar as normas trabalhistas com as mudanças decorrentes da ordem econômica mundial e seus inegáveis golpes nos direitos sociais dos trabalhadores.

Dessa forma, o Estado detém uma enorme responsabilidade no sentido de compatibilizar o desenvolvimento econômico e a garantia dos direitos sociais dos trabalhadores, haja vista que ambos são de extrema importância para o desenvolvimento nacional sustentável. Um garante que o país permaneça em desenvolvimento, e o outro, em contrapartida, freia possíveis infrações aos direitos dos trabalhadores adquiridos por meio de inúmeras conquistas sociais.

\section{Considerações finais}

Diante do exposto, verifica-se que a intervenção do Estado para garantir o progresso e o desenvolvimento econômico nacional é de extrema importância nestes tempos de crise econômica e financeira mundial e do processo "precoce" de desindustrialização nacional. Isso deve ocorrer seja com investimentos nas de áreas de saúde, educação, tecnologia, transporte, infraestrutura, etc., seja na desoneração tributária e trabalhista para as empresas brasileiras (grande, médio ou pequeno porte).

O que deve nortear os Estados é a consequência "futura" dessa crise, tanto no mercado financeiro mundial quanto nas relações de 
trabalho e emprego, pois um depende do outro. Segundo Cunha (2009, p. 355),

registre-se que o fenômeno do desemprego sempre foi comum a todos os povos e economias, mas o que se realça aqui é que, provavelmente, o mundo vivenciará um período de escassez de emprego como nunca ocorrido, verificando-se grande quantidade de desempregados em expressivos espaços de tempo sem trabalho, pelo que não se descarta nova submissão da ordem moral ao mercado, com uma possível tolerância ao trabalho infantil e prostituição (inclusive infantil), dentre outras atividades atualmente consideradas degradantes.

O Estado deve incentivar o desenvolvimento nacional por meio de medidas que sejam sustentáveis, ou seja, medidas compatíveis com as necessidades nacionais e que não comprometam os direitos individuais e sociais fundamentais garantidos na Constituição Federal.

Outro ponto salutar é que o Estado neste momento é a solução para fortalecer e reorientar as políticas governamentais de geração e proteção do emprego e renda, uma vez que o Estado Democrático de Direito tem por fundamento a valorização social do trabalho e da livre-iniciativa.

Vale lembrar ainda que as medidas federais mencionadas ao longo deste artigo são algumas de muitas que devem ser emanadas pelo Governo para que o Brasil não tenha um processo efetivo de desindustrialização nacional, de aumento no desemprego estrutural e ainda na precarização e flexibilização das normas e das condições de trabalho.

\section{Referências}

BANCO NACIONAL DE DESENVOLVIMENTO ECONÔMICO E SOCIAL BNDES. Associados a projeto de investimento. Disponível em: $<\mathrm{http}: / / w w w$. bndes.gov.br/SiteBNDES/bndes/bndes_pt/Institucional/Apoio_Financeiro/ Programas_e_Fundos/Psi/psi_bk.html >. Acesso em: 28 maio 2012. 
BRASIL. Presidência da República. Lei n. 7.102, de 20 de junho de 1983. Dispõe sobre segurança para estabelecimentos financeiros, estabelece normas para constituição e funcionamento das empresas particulares que exploram serviços de vigilância e de transporte de valores, e dá outras providências. Diário Oficial [da] República Federativa do Brasil, Poder Legislativo, Brasília, DF, 20 jul. 1983. Disponível em: 〈http://www.planalto.gov.br/ccivil_03/leis/L7102.htm〉. Acesso em: 23 dez. 2011.

BRASIL. Presidência da República. Lei n. 9.472, de 16 de julho de 1997. Dispõe sobre a organização dos serviços de telecomunicações, a criação e funcionamento de um órgão regulador e outros aspectos institucionais, nos termos da Emenda Constitucional n. 8, de 1995. Diário Oficial [da] República Federativa do Brasil, Poder Legislativo, Brasília, DF, 16 jul. 1997. Disponível em: <http://www. planalto.gov.br/ccivil_03/leis/L9472.htm>. Acesso em: 23 dez. 2011.

BRASIL. Presidência da República. Lei n. 6.019, de 3 de janeiro de 1974. Dispõe sobre o Trabalho Temporário nas Empresas Urbanas, e dá outras Providências. Diário Oficial [da] República Federativa do Brasil, Poder Legislativo, Brasília, DF, 3 jan. 1974. Disponível em: <http://www.planalto.gov.br/ccivil_03/ leis/L6019.htm>. Acesso em: 23 dez. 2011.

CUNHA, F. S. da. Crise econômica e possíveis perspectivas jurídico-sociais. Revista de Direito GV, v. 5, n. 2, p. 343-358, 2009.

FEDERAÇÃO DAS INDÚSTRIAS DO PARANÁ - FIEP. Indústria da região sul busca soluções para o setor têxtil e de vestuário. Disponível em: <http:// www.agenciafiep.com.br/noticia/industria-da-regiao-sul-busca-solucoes-para-o-setor-textil-e-de-vestuario/>. Acesso em: 29 jun. 2012.

IMPRENSA NACIONAL. Ministério da Saúde dará preferência a produtos nacionais em compras públicas. Disponível em: $<\mathrm{http}$ ://www2.planalto.gov. $\mathrm{br} /$ imprensa/noticias-de-governo/ministerio-da-saude-dara-preferencia-a-produtos-nacionais-em-compras-publicas $>$. Acesso em: 5 abr. 2012.

LEDUR, J. F. Direitos fundamentais sociais: efetivação no âmbito da democracia participativa. Porto Alegre: Livraria do Advogado, 2009.

Rev. Direito Econ. Socioambiental, Curitiba, v. 3, n. 2, p. 355-373, jul./dez. 2012 
MEDEIROS, A. A. A. de. Estado, crise econômica mundial e a centralidade do trabalho. Revista Internacional de Direito e Cidadania, n. 8, p. 7-15, 2010.

NASSIF, A. Há evidências de desindustrialização no Brasil? Revista Economia Politica, v. 28, n. 1, p. 72-96, 2008. doi: 10.1590/S0101-31572008000100004.

ORGANIZAÇÃO DOS ESTADOS AMERICANOS. Conselho Interamericano de Desenvolvimento Integral - CIDI. 2011. Disponível em: <http://www.oas. org/ddse/english/cpo_trab_grupo1.asp>. Acesso em: 29 jun. 2012.

PELED, M. China Blue. Disponível em: <http://teddybearfilms.fatcow.com/ 2011/09/01/china-blue/>. Acesso em: 29 jun. 2012.

PIOVESAN, F. (Coord.). Direitos humanos, globalização econômica e integração regional: desafios do Direito Constitucional Internacional. São Paulo: Max Limonad, 2002.

RESENDE, R. Direito do trabalho esquematizado. 2. ed. São Paulo: Método, 2012.

SONAGLIO, C. M. et al. Desindustrialização no Brasil. Revista Economia Aplicada, v. 14, n. 4, p. 347-372, 2010.

WATANABE, M. O Brasil tem o quinto menor custo de produção em ranking de 14 países. Disponível em: <https://conteudoclippingmp.planejamento.gov. br/cadastros/noticias/2012/4/2/brasil-tem-quinto-menor-custo-de-producao-em-ranking-de-14-paises >. Acesso em: 29 jun. 2012.

Recebido: 16/08/2011

Received: 08/16/2011

Aprovado: 12/07/2012

Approved: 07/12/2012 